\title{
Electricity Market Environment
}

\author{
Trivedi Forum Kashyap", Prof. R. A. Patel $^{2}$ \\ M.Tech Student, Electrical, Ganpat University, Mehsana, India ${ }^{1}$ \\ Associate Professor, Electrical, Ganpat University, Mehsana, India ${ }^{2}$
}

\begin{abstract}
The work presented here consists of detailed understanding of general market, electrical market, need of electricity markets and its objectives. All the entities and its role indulged in the electricity market architecture are also mentioned. It involves detailed classification of electrical market, the role of Independent System Operator which includes its responsibilities, principles, prescriptions and activities thereby. The paper focusses on the Generating Company (GENCO) which expresses the behaviour of genco in pool and bilateral markets. To accomplish the task, some statistical data related to the generating company are being shown. And at last, the load forecasting using Statistical Model based learning method is being carried out for different days. The percentage deviation of Actual drawl and Final schedule is being presented which clearly shows the variation is between 5 to 10 percent.
\end{abstract}

Keywords: Electrical Market, Genco.

\section{INTRODUCTION}

A market is an actual or nominal place where forces of demand and supply operate and where buyers and sellers interact (directly or through intermediaries) to trade goods, services or contracts or instruments, for money or barter.

Market include mechanisms or means for:

1. Determining price of the traded item.

2. Communicating the price information.

3. Facilitates deals and transactions.

4. Effecting distribution.

The market for a particular item is made up of existing and potential customers who need it and have the ability and willingness to pay for it. An electricity market is a system enabling purchases, through bids to buy, sales through offers to sell and short term trades, generally in the form of financial or obligation swaps. Bids and offers use supply and demand principles to set the price.

The commodities with in an electricity market generally consists of two types: i.e., power and energy. Electricity markets are highly complex systems that consists of a number of inter-related markets for different commodities i.e., Energy, Transmission, Ancillary services \& Different time frames (real-time, hour-ahead and day-ahead). The structure of this whole market is known as Electrical Market Environment. The need of electricity market environment is that the marketization is the only way for power industry to lead to prosperity.

The electricity market provide efficient operation of electricity with respect to;

1. Price, quality, safety, reliability electricity.

2. Reliability, safety, and security of the national electricity system.

\section{ELECTRICAL MARKET ARCHITECTURE.}

The electricity market architecture comprises of main four entities namely; Gencos, Transcos, Discos \&An Independent System Operator.[1]

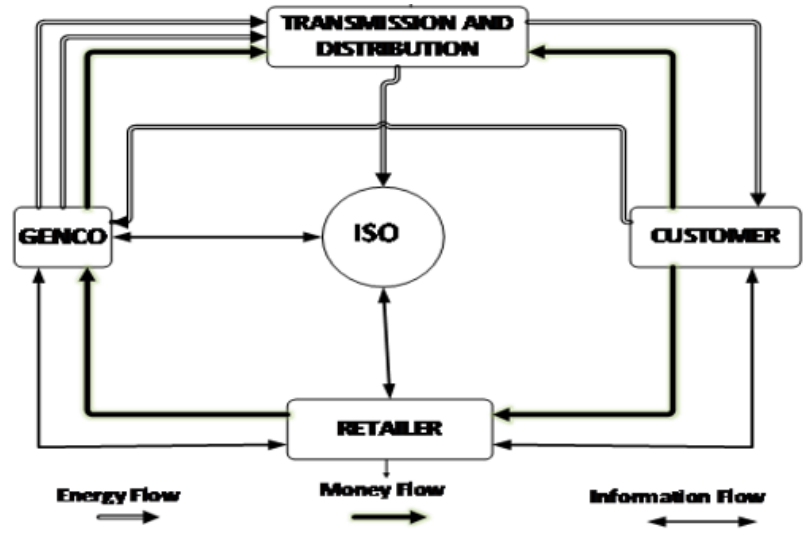

Figure-1 Electricity Market Architecture

\section{A. Generating Companies (Gencos)}

Genco is an owner-operator of one or more generators that runs them and bids the power into the competitive market place. Genco is not necessary to have its own generating plants, but it can negotiate on behalf of generating companies.

\section{B. Transmission Companies (Transcos)}

The transmission companies are those entities, which own and operate transmission lines. Their prime responsibility is to transport the electricity from the generators to the customer, and making available the transmission wires to all entities in the system. For their services, they levy a transmission tariff.

\section{Distribution Companies (Discos)}

The distribution companies are those entities owing and operating the local distribution network in an area. They buy wholesale electricity either through the spot-market or through direct contracts with gencos and supply electricity to the end-use customers

\section{Independent System Operator (ISO)}

The ISO is an entity entrusted with the responsibility of ensuring the reliability and security of the entire system. It is an independent authority and does not participate in the electricity market trades. 
INTERNATIONAL JOURNAL OF INNOVATIVE RESEARCH IN ELECTRICAL, ELECTRONICS, INSTRUMENTATION AND CONTROL ENGINEERING Vol. 4, Issue 1, January 2016

E. Customers

A customer is an entity consuming electricity. In deregulated markets, the customer has several options for buying electricity.

\section{F. Retailers}

It is the retailer of electric power. Many of these will be the retail departments of the former vertically integrated utility.

\section{DETAILED CLASSIFICATION OF ELECTRICAL MARKET}

Classification according to Power Market:-
A. Energy market.
B. Ancillary services market.
C. Transmission markets

Classification according to operating mechanism of market:-

D. Forward market.

E. Spot market.

F. Pool market.

Other Market Types:-

G. Whole sale market.

H. Retail market.

a. Energy Market.

The energy market is where the competitive trading of electricity occurs. The energy market is a centralized mechanism that facilitates energy trading between buyers and sellers. The energy market's prices are reliable prices indicators, not only for market participants but for other financial markets and consumers of electricity as well.

\section{b. Ancillary Services Market}

Ancillary services are needed for the power system to operate reliably. In the regulated industry, ancillary services are mandated to be unbundled with energy. In the general, ancillary bids submitted by the market participants consists of two parts i.e., A Capacity Bid \&An Ancillary Bid.

\section{c. Transmission Market}

In a restructured power system, the transmission network is where competition occurs among suppliers in the meeting, the demands of large users and distribution companies. The commodity traded in the transmission market is a transmission right.

\section{d. Forward Market}

There are two types of forward market i.e., A Day-ahead Forward Market \& An Hour-ahead Forward Market.

In the day-ahead market and for each hour of the 24-hour scheduling day, sellers bid a schedule of supply at various prices, and MCP is determined for each hour. Then, sellers specify the resources for the sold power, and the buyers specify the delivery points for the purchased power.

The hour-ahead market is similar to the day-ahead, except trades are for one hour, and the available transfer capability (ATC) is reduced to include day-ahead trades, and the bids are not iterative in this market.

\section{e. Spot Market}

Spot market is also known as real time market. To ensure the reliability of power system, the production and consumption of electric power must be balanced in real time.

\section{f. Pool Market}

It is defined as a centralized market place that clears the market for buyers and sellers where electric power sellers/buyers submit bids and prices into the pool for the amounts of energy that they are willing to sell/buy. In the pool market model, there are two main sides of entities participating in the market, i.e. customer and supplier.

\section{g. Whole-sale Electricity Market}

This market provides a competitive environment for generators, because the whole sale price is determined by the interaction between supply and demand.[2]

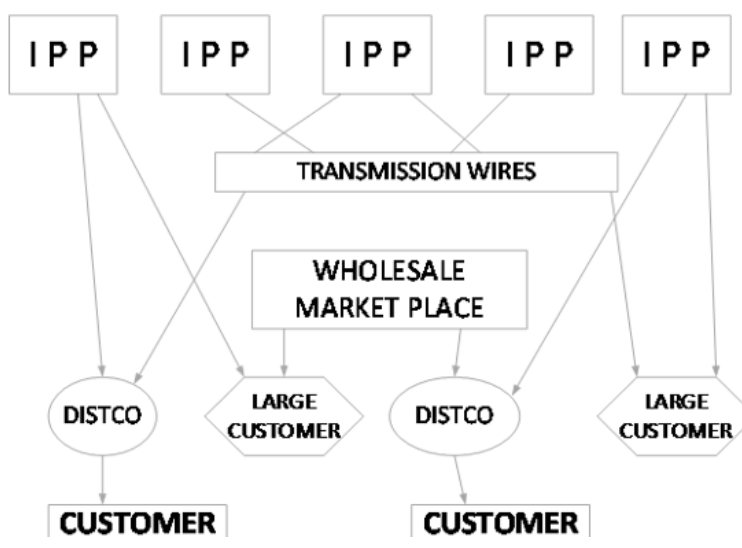

Figure-2 Whole-Sale Electricity Market

h. Retail Electricity Market

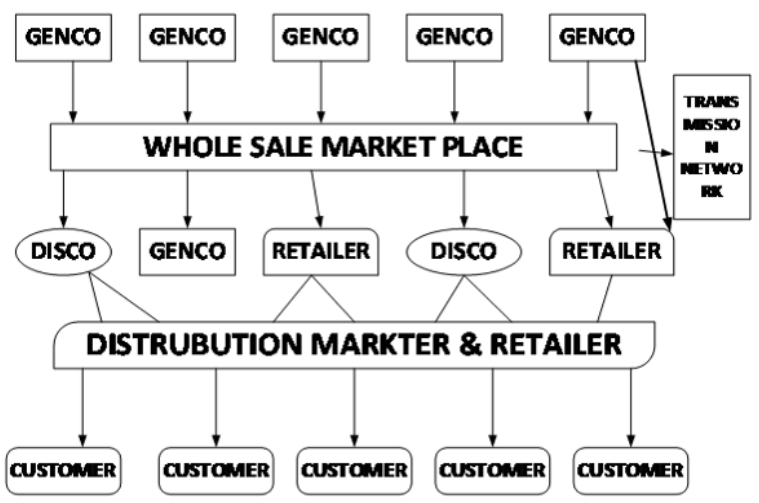

Figure-3 Retail Electricity Market

In this model, as shown in Figure 3, all customers have access to competing generators either directly or through their choice of retailer. This would have complete separation of both generation and retailing from the transport business at both transmission and distribution levels.

\section{THE INDEPENDENT SYSTEM OPERATOR (ISO)}

a. Responsibilities of an Independent System Operator The primary objective of the ISO is not dispatching or redispatching generation, but matching electricity supply with demand as necessary to ensure reliability. The ISO 
should control generation to the extent necessary to maintain reliability and optimize transmission efficiency.[3]

\section{b. Principles for The Independent System Operator}

In its order number 888 , FERC developed 11 principles as guidelines to the electric industry restructuring to form a properly constituted ISO, through which public utilities could comply with FERC's non-discriminatory transmission tariff requirements.

\section{c. Prescriptions for The ISO's}

There are few essential services related to coordinating use of the transmission grid where the ISO is both necessary and would have a significant comparative advantage. For example, although it is possible to design an ISO that ignores market preferences, the ISO would have a significant advantage in conducting its short-term coordination activities through an open spot market.

\section{d. Activities of the ISO}

A. In Pool Market.

The activities of ISO in a pool can be classified as follows;

a. 24-hours ahead.

b. In real-time.

c. After real-time.

\& The activities Bilateral Market is also classified according to 24-hours ahead, in real-time and after real-time.[4]

\section{GENERATING COMPANY (GENCO)}

Genco is one of the entity of the electricity market architecture. In an ancillary market, genco has an opportunity to sell its reserves and reactive power.

\section{A. The Genco in Pool Market.}

In an ancillary market, genco has an opportunity to sell its reserves and reactive power. In some markets, the gencos are also requires to provide start-up price offers, ramp rates, minimum up and down time as shown in the table given below.

\begin{tabular}{|c|l|l|}
\hline Market & $\begin{array}{l}\text { Information received by the } \\
\text { market operator through bids }\end{array}$ & $\begin{array}{l}\text { Who is responsible for unit } \\
\text { commitment }\end{array}$ \\
\hline UK & $\begin{array}{l}\text { Energy price, start-up price, } \\
\text { offered capacity, ramp up rate, } \\
\text { ramp down rate, minimum } \\
\text { generation level, minimum up } \\
\text { time, minimum down time. }\end{array}$ & $\begin{array}{l}\text { ISO- the National Grid Company } \\
\text { plc. }\end{array}$ \\
\hline NY & $\begin{array}{l}\text { Energy price, start-up costs, } \\
\text { minimum generation level, } \\
\text { maximum generation level. }\end{array}$ & $\begin{array}{l}\text { Self commitment by individual } \\
\text { genco. }\end{array}$ \\
\hline PJM & Same as NY. & PJM-ISO. \\
\hline NZEM & $\begin{array}{l}\text { Energy prices, ramp rate limits, } \\
\text { reserve bids. }\end{array}$ & $\begin{array}{l}\text { Self commitment by individual } \\
\text { gencos. The ramp rate limits } \\
\text { submitted to the ISO are adhered } \\
\text { to, in the bid clearing process. }\end{array}$ \\
\hline Nordic & $\begin{array}{l}\text { Energy price and quantity for both } \\
\text { buying and selling. There is also a } \\
\text { short term market for trade close to } \\
\text { real time. }\end{array}$ & $\begin{array}{l}\text { Self commitment by individual } \\
\text { gencos. }\end{array}$ \\
\hline
\end{tabular}

Table-1 Generation Scheduling Practices in different Electricity Markets.

\section{B. The Genco in Bilateral Market.}

In bilateral markets, the gencos enter into direct buy and sell contracts with selling/buying agents.

\section{A. 24- Hours Ahead}

24- Hours ahead activity contains Entitlement, Generator schedule, Drawl schedule.

Entitlement means every discos are given some share from gencos as per their installed capacity. Sample TAECO SP (TorrentAhmedabad electricity company) has entitlement is as below in 96 slots of 15 mins for 12.10.15. [5]

Generator schedule means gencos have to submit the generator wise generating schedule in 96 slots of 15 mins before 24-hours. The sample Generator GTPS 5Gandhinagar Thermal Power station unit 5 gives its generation schedule in 96 slots for UGVCL \& PGVCL as per entitlement of 12.10.15.[6]

Drawl schedule means every discos have to give their load demand (generator wise as per entitlement) in 96 slots 24 hours ahead for next day. Drawl schedule for TAECOTorrent Ahmedabad Electricity company for 12.10.15 is as below.[7]

\section{B. In Real-Time.}

The Sample screen shot is as below from Gujarat SLDC site which shows the installed capacity of Gujarat gencos, schedule \& actual generation. It also shows the Gujarat Discos schedule, actual drawl and Deviation between schedule and drawl as DSM.[8]

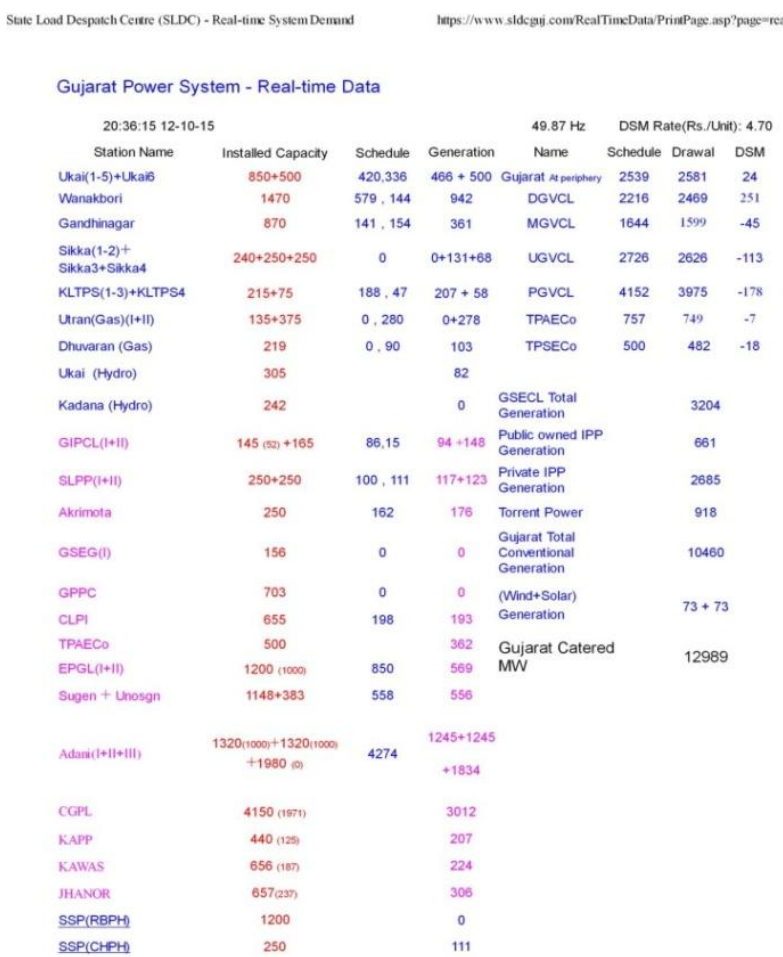

Figure-4 Gujarat Power System Real Time Data [8]

UGVCL-PGVCL SCHEDULE VS DRAWL TREND- It shows UGVCL schedule is much closer than PGVCL. Which suggest that on this day scheduling of UGVCL is much better. Scheduling is done 24 hours ago.[9]

After monitoring of ISO the trend for power in Gujarat for 08.10.15 is as below. In which schedule and drawl is nearer to each other which is good sing and that's why the frequency variation is very low, which is very important for system reliability. 
INTERNATIONAL JOURNAL OF INNOVATIVE RESEARCH IN ELECTRICAL, ELECTRONICS, INSTRUMENTATION AND CONTROL ENGINEERING Vol. 4, Issue 1, January 2016

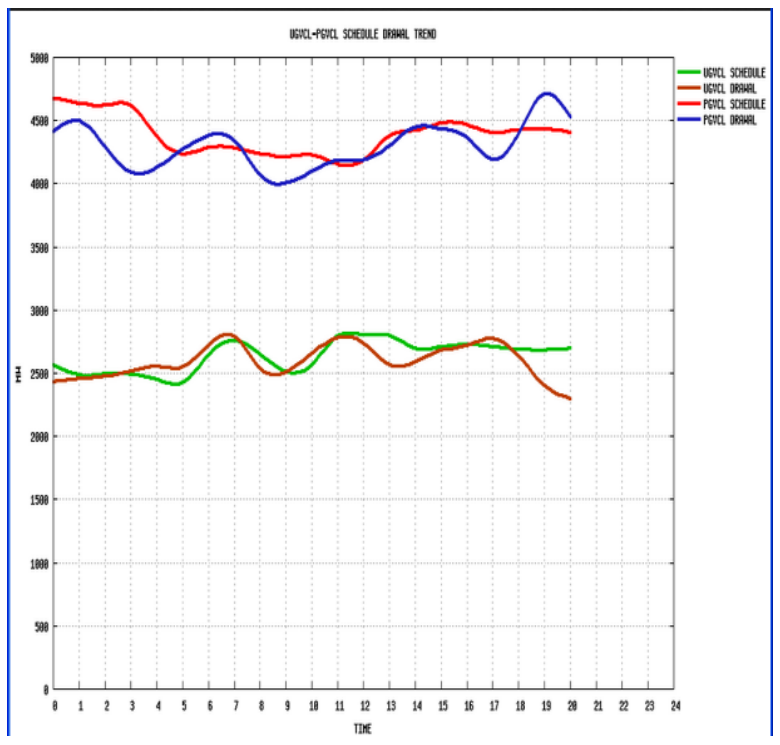

Figure-5 Ugvcl-Pgvcl Schedule V/S Drawl Trend [9]

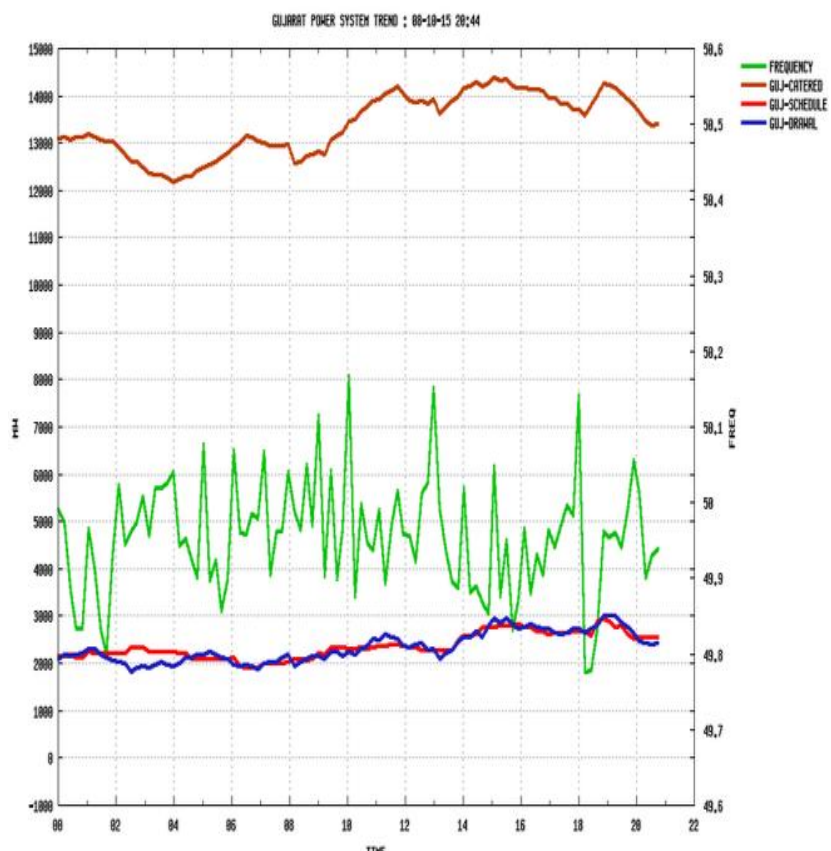

Figure-6 Trend for Power in Gujarat for 08-10-2015 [10]

\section{Load Forecasting}

The forecasting of UGVCL is done using Statistical Model based learning method.

\begin{tabular}{|c|c|c|c|c|}
\hline HOUR & ENTITLEMENT & $\begin{array}{c}\text { DAY AHEAD } \\
\text { SCHEDULE }\end{array}$ & $\begin{array}{c}\text { FINAL } \\
\text { REVISED } \\
\text { SCHEDULE }\end{array}$ & $\begin{array}{c}\text { ACTUAL } \\
\text { DRAWL }\end{array}$ \\
\hline 1 & 3149.40 & 2937.86 & 2419.36 & 2366.00 \\
\hline 2 & 3147.34 & 2936.38 & 2494.28 & 2394.25 \\
\hline 3 & 3144.62 & 2936.10 & 2492.91 & 2381.50 \\
\hline 4 & 3158.79 & 2935.53 & 2529.56 & 2339.00 \\
\hline 5 & 3157.66 & 2934.93 & 2553.42 & 2310.00 \\
\hline 6 & 3153.54 & 2944.73 & 2562.83 & 2297.75 \\
\hline 7 & 3150.03 & 2941.38 & 2509.32 & 2518.50 \\
\hline 8 & 3151.60 & 2941.86 & 2597.20 & 2686.50 \\
\hline 9 & 3158.99 & 2950.14 & 2514.94 & 2538.25 \\
\hline 10 & 3166.67 & 2956.28 & 2525.58 & 2535.00 \\
\hline 11 & 3175.77 & 2961.67 & 2525.72 & 2673.50 \\
\hline 12 & 3191.54 & 2966.96 & 2750.15 & 2938.00 \\
\hline
\end{tabular}

Table-2 Entitlement, Schedule and Drawl schedule of UGVCL for 18-10-15.

Entitlement is the power available for scheduling. Day ahead is the schedule done before 24 hours. Final revised schedule is the final schedule after revision done during the day as per load position. Actual drawl is the actual drawl done.

Based on the table [11], a graph of UGVCL's entitlement, schedule and drawl for 18-10-2015 is shown below.

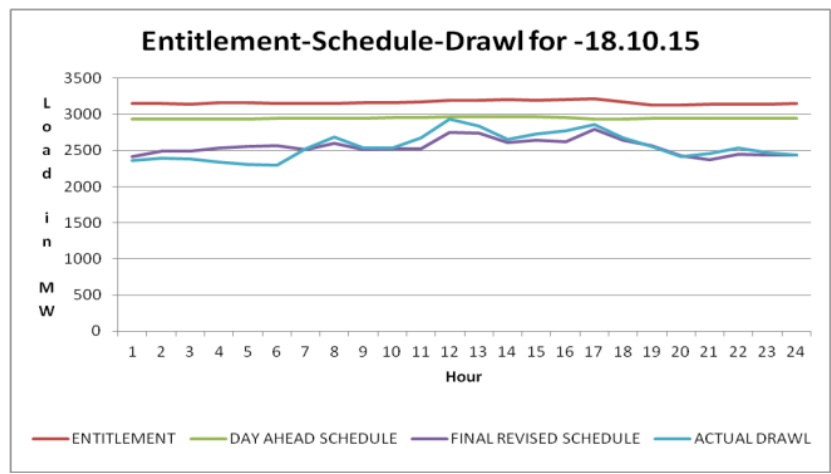

Figure-7 Graph of Entitlement, Schedule and Drawl of UGVCL for 18-10-15.

The graph consists of load in MW versus hour. Thus, it can be clearly seen that the entitlement and day ahead schedule is almost constant, whereas final revised schedule and actual drawl is between $2500 \mathrm{MW}$ to 3000 MW.

\begin{tabular}{|c|c|c|c|c|}
\hline HOUR & ENTITLEMENT & $\begin{array}{c}\text { DAY AHEAD } \\
\text { SCHEDULE }\end{array}$ & $\begin{array}{c}\text { FINAL } \\
\text { REVISED } \\
\text { SCHEDULE }\end{array}$ & $\begin{array}{c}\text { ACTUAL } \\
\text { DRAWL }\end{array}$ \\
\hline 1 & 3269.31 & 2701.76 & 2252.91 & 2292.25 \\
\hline 2 & 3265.44 & 2701.89 & 2357.37 & 2336.25 \\
\hline 3 & 3256.24 & 2701.85 & 2395.77 & 2340.00 \\
\hline 4 & 3254.38 & 2701.35 & 2246.91 & 2329.75 \\
\hline 5 & 3254.29 & 2699.94 & 2209.62 & 2285.50 \\
\hline 6 & 3253.88 & 2698.24 & 2208.88 & 2267.75 \\
\hline 7 & 3249.18 & 2696.28 & 2203.95 & 2459.00 \\
\hline 8 & 3248.29 & 2698.01 & 2203.47 & 2578.25 \\
\hline 9 & 3254.70 & 2704.85 & 2203.21 & 2376.50 \\
\hline 10 & 3265.86 & 2711.47 & 2217.17 & 2311.75 \\
\hline 11 & 3275.46 & 2720.36 & 2329.70 & 2397.75 \\
\hline 12 & 3285.94 & 2730.90 & 2434.20 & 2593.25 \\
\hline
\end{tabular}

Table-3 Entitlement, Schedule and Drawl schedule of UGVCL for 22-10-15.

Based on the table [12], a graph of UGVCL's entitlement, schedule and drawl for 22-10-2015 is shown below.

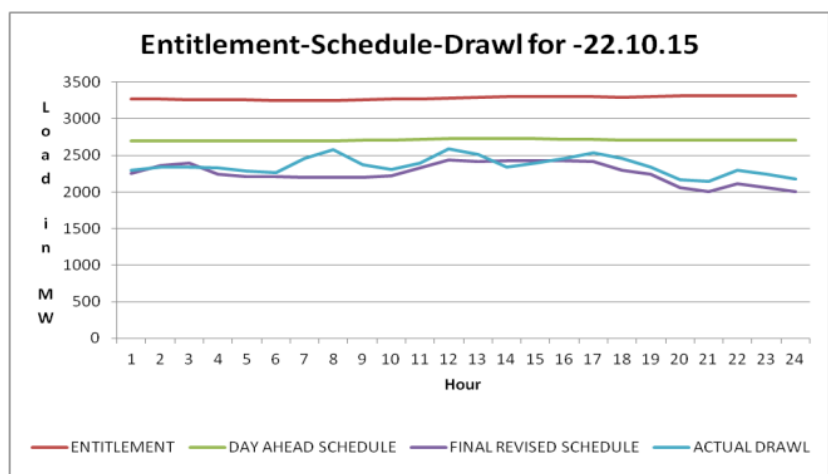

Figure-8 Graph of Entitlement, Schedule and Drawl of UGVCL for 22-10-15.

The graph consists of load in MW versus hour. Thus, it can be clearly seen that the entitlement and day ahead schedule is almost constant, whereas final revised schedule and actual drawl is between $2000 \mathrm{MW}$ to 3000 MW. 
INTERNATIONAL JOURNAL OF INNOVATIVE RESEARCH IN ELECTRICAL, ELECTRONICS, INSTRUMENTATION AND CONTROL ENGINEERING Vol. 4, Issue 1, January 2016

\begin{tabular}{|c|c|c|c|c|}
\hline HOUR & ENTITLEMENT & $\begin{array}{c}\text { DAY AHEAD } \\
\text { SCHEDULE }\end{array}$ & $\begin{array}{c}\text { FINAL } \\
\text { REVISED } \\
\text { SCHEDULE }\end{array}$ & $\begin{array}{c}\text { ACTUAL } \\
\text { DRAWL }\end{array}$ \\
\hline 1 & 3224.97 & 2472.05 & 2168.45 & 2275.75 \\
\hline 2 & 3223.13 & 2471.50 & 2143.07 & 2275.00 \\
\hline 3 & 3220.89 & 2470.37 & 2140.52 & 2256.00 \\
\hline 4 & 3220.49 & 2468.65 & 2090.12 & 2201.50 \\
\hline 5 & 3219.22 & 2466.56 & 2088.53 & 2174.25 \\
\hline 6 & 3206.05 & 2463.53 & 2107.67 & 2232.50 \\
\hline 7 & 3208.79 & 2460.39 & 2392.35 & 2392.75 \\
\hline 8 & 3212.11 & 2463.62 & 2474.31 & 2601.75 \\
\hline 9 & 3217.90 & 2474.20 & 2416.81 & 2539.50 \\
\hline 10 & 3230.96 & 2486.83 & 2406.63 & 2589.75 \\
\hline 11 & 3243.06 & 2499.99 & 2530.21 & 2763.75 \\
\hline 12 & 3252.88 & 2509.71 & 2754.11 & 2970.50 \\
\hline
\end{tabular}

Table-4 Entitlement, Schedule and Drawl schedule of UGVCL for 25-10-15.

Based on the table [13], a graph of UGVCL's entitlement, schedule and drawl for 25-10-2015 is shown below.

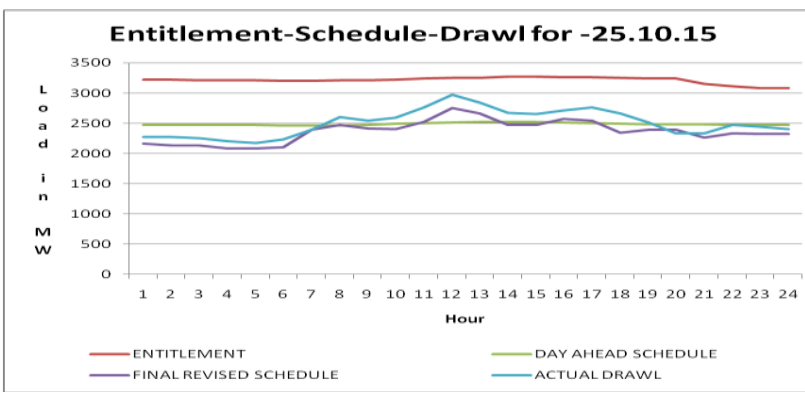

Figure-9 Graph of Entitlement, Schedule and Drawl of UGVCL for 25-10-15.

The graph consists of load in MW versus hour. Thus, it can be clearly seen that the entitlement and day ahead schedule is almost constant, whereas final revised schedule and actual drawl is between $2000 \mathrm{MW}$ to 3000 MW.

\begin{tabular}{|c|c|c|c|c|}
\hline HOUR & ENTITLEMENT & $\begin{array}{c}\text { DAYAHEAD } \\
\text { SCHEDULE }\end{array}$ & $\begin{array}{c}\text { FINAL } \\
\text { REVISED } \\
\text { SCHEDULE }\end{array}$ & $\begin{array}{c}\text { ACTUAL } \\
\text { DRAWL }\end{array}$ \\
\hline 1 & 3078.58 & 2563.91 & 2005.02 & 1992.61 \\
\hline 2 & 3089.64 & 2568.47 & 2025.08 & 2027.04 \\
\hline 3 & 3099.21 & 2576.14 & 1958.94 & 2027.04 \\
\hline 4 & 3113.05 & 2585.48 & 1965.14 & 2018.54 \\
\hline 5 & 3124.29 & 2595.98 & 1947.04 & 1984.75 \\
\hline 6 & 3143.24 & 2628.16 & 2226.54 & 2061.46 \\
\hline 7 & 3156.33 & 2637.95 & 2311.83 & 2162.83 \\
\hline 8 & 3172.75 & 2650.84 & 2325.75 & 2278.85 \\
\hline 9 & 3189.78 & 2654.26 & 2367.25 & 2242.51 \\
\hline 10 & 3186.84 & 2652.64 & 2515.62 & 2272.26 \\
\hline 11 & 3179.66 & 2652.65 & 2568.56 & 2282.04 \\
\hline 12 & 3116.80 & 2653.48 & 2468.34 & 2447.36 \\
\hline
\end{tabular}

Table-5 Entitlement, Schedule and Drawl schedule of UGVCL for 28-10-15.

Based on the table [14], a graph of UGVCL's entitlement, schedule and drawl for 28-10-2015 is shown below.

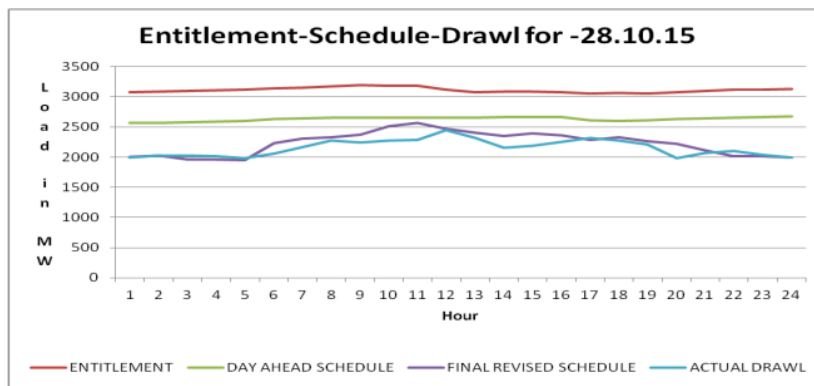

Figure-10 Graph of Entitlement, Schedule and Drawl of UGVCL for 28-10-15.

The graph consists of load in MW versus hour. Thus, it can be clearly seen that the entitlement and day ahead schedule is almost constant, whereas final revised schedule and actual drawl is between $2000 \mathrm{MW}$ to 3000 MW.

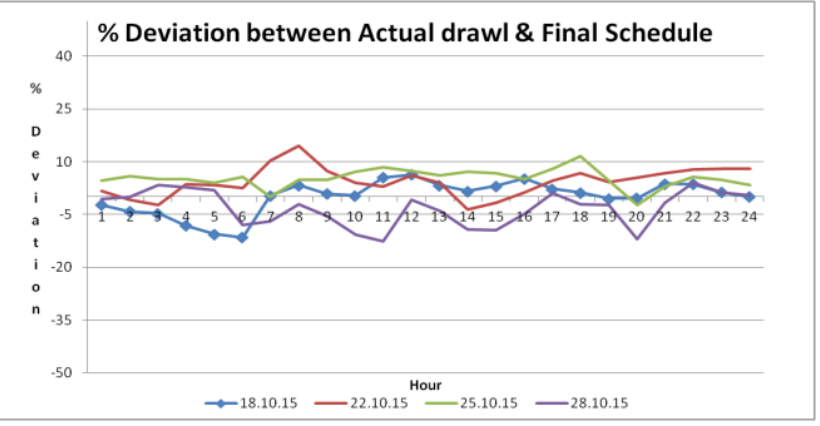

Figure-11 Graph of Percentage Deviation between Actual Drawl and Final Schedule for 18-10-15, 22-10-15, 25-1015 , and $28-10-15$.

The graph consists of Percentage Deviation versus hour. Thus, it can be clearly seen that the variation between actual drawl and final schedule is 5 to 10 percent.

\section{After Real-Time}

After day ahead and real time monitoring by ISO, the billing/ settlement is most important work, in which you have to monitor gap between schedule and actual drawl, the frequency at that time \& the DSM charge at that time. It is very lengthy process.

\section{ACKNOWLEDGEMENT}

I would like to thank Prof. R. A. Patel from my heart and soul for giving me ability to prepare the paper. I express my humble gratitude towards him who guided me through out and encouraged at every step in this exercise and giving me a chance to work on such a useful and interesting topic and for providing me with his supportive guidance till the completion of the paper. Without their guidance and help, this would neither have been possible nor in its present shape. I am very thankful to my parents who supported me the way they can also and at last but not least my sincere thanks to all my friends who supported me and inestimable help in providing me the necessary information and also during the preparation of my paper. Because without their support, the completion would not have been possible. It is their love that keeps me moving forward.

\section{CONCLUSION}

In the proposed paper, a brief introduction about general market and electrical market is shown. A detailed explanation of electrical market architecture and its classification is also carried out. The role of generating company (Genco) in pool and bilateral markets is analysed from the activities of the Independent System Operator (ISO). Also the load forecasting of UGVCL is done using statistical model based learning method which consists of entitlement, schedule and drawl schedule for different days. And at last, combined percentage deviation between actual, drawl and final schedule is made which clearly shows that the variation between actual, drawl and final schedule is 5 to 10 percent. 
INTERNATIONAL JOURNAL OF INNOVATIVE RESEARCH IN ELECTRICAL, ELECTRONICS, INSTRUMENTATION AND CONTROL ENGINEERING Vol. 4, Issue 1, January 2016

\section{REFERENCES}

[1] Kankar Bhattacharya, Math H.J. Bollen, and Jaap E. Daalder "Operation and Restructured Power Systems"Chaalmers University of Technology.

[2] N. S. Modi, Member IEEE, B. R. Parekh "Transmission Network Congestion in De-Regulated Whole-Sale Market, Proceedings Of the International Multi-Conference Of Engineers \& Computer Scientists 2009 Vol II IMECS 2009, March 18-20, March 2009, Hongkong.

[3] William W. Hogan "Independent System Operator (ISO) for a competitive electricity market", Harvard University.

[4] SurachaiChaitusaney, Student \& BundhitEua-Arporn," Actual Social Welfare Maximization in Pool Market", Member, IEEE

[5] Entitlement Of Sample TAECO SP (Torrent Ahmedabad Electricity Company) Of 12/10/15.

[6] Generator Schedule Of GTPS5- Gandhinagar Thermal Power Station For UGVCL \& PGVCL as per Entitlement of 12/10/15.

[7] Drawl Schedule For TAECO-Torrent Ahmedabad Electricity Company.

[8] Sample from Gujarat SLDC Site which shows installed Capacity Of Gujarat GENCOS, Schedule \& Actual Generation, "www.sldc.guj.com".

[9] UGVCL-PGVCL Schedule versus Drawl Trend, "www.sldc.guj.com".

[10] Trend for power in Gujarat for 08-10-2015, "www.sldc.guj.com".

[11] Detailed table of the entitlement, schedule and drawl of UGVCL for 18-10-2015 for 24 hours.

[12] Detailed table of the entitlement, schedule and drawl of UGVCL for 22-10-2015 for 24 hours.

[13] Detailed table of the entitlement, schedule and drawl of UGVCL for 25-10-2015 for 24 hours.

[14] Detailed table of the entitlement, schedule and drawl of UGVCL for 28-10-2015 for 24 hours. 